\title{
ARTICLE \\ Cancer stem-like cells can be induced through dedifferentiation under hypoxic conditions in glioma, hepatoma and lung cancer
}

\author{
Pan Wang ${ }^{1}$, Wen-wu Wan ${ }^{1}$, Shuang-Long Xiong ${ }^{2}$, Hua Feng ${ }^{1}$ and Nan $\mathrm{Wu}^{1}$
}

Traditional studies have shown that transcription factors, including SOX-2, OCT-4, KLF-4, Nanog and Lin-28A, contribute to the dedifferentiation and reprogramming process in normal tissues. Hypoxia is a physiological phenomenon that exists in tumors and promotes the expression of SOX-2, OCT-4, KLF-4, Nanog and Lin-28A. Therefore, an interesting question is whether hypoxia as a stimulating factor promotes the process of dedifferentiation and induces the formation of cancer stem-like cells. Studies have shown that OCT-4 and Nanog overexpression induced the formation of cancer stem cell-like cells through dedifferentiation and enhanced malignancy in lung adenocarcinoma, and reprogramming SOX-2 in pancreatic cancer cells also promoted the dedifferentiation process. Therefore, we investigated this phenomenon in glioma, lung cancer and hepatoma cells and found that the transcription factors mentioned above were highly expressed under hypoxic conditions and induced the formation of spheres, which exhibited asymmetric division and cell cycle arrest. The dedifferentiation process induced by hypoxia highlights a new pattern of cancer development and recurrence, demonstrating that all kinds of cancer cells and the hypoxic microenvironment should be taken into consideration when developing tumor therapies.

Cell Death Discovery (2017) 3, 16105; doi:10.1038/cddiscovery.2016.105; published online 23 January 2017

\section{INTRODUCTION}

Dedifferentiation, as a universal biological phenomenon, involves the regression from a specialized differentiated tissue to a stem cell-like state with retained self-renewal properties. Stem cells, particularly embryonic stem cells, have had a vital role in degenerative diseases and regenerative medicine but remain an issue of ethical morality, and their use in studies is thus controversial. To avoid this, researchers have successfully induced the formation of pluripotent stem cells (iPSCs) from adult fibroblasts or other somatic cells using defined transcription factors, including SOX-2, OCT-4, KLF-4, Nanog, LIN-28A and C-MYC. ${ }^{1-4}$ Hence, these transcription factors contribute significantly to the dedifferentiation process in normal tissues. However, an interesting question is what the influences of these factors on cancer stem cells (CSCs) are. CSCs, as another type of stem cells, have been shown to contribute to tumor recurrence, resistance to chemo- and radiotherapy and malignant development., ${ }^{5,6}$ Recently, a series of studies demonstrated that these transcription factors are highly expressed in glioma, ${ }^{7}$ pancreatic cancer, ${ }^{8,9}$ breast cancer, ${ }^{10}$ lung adenocarcinoma ${ }^{11}$ and hepatoma. ${ }^{12}$ In 2010, Chiou et al. ${ }^{11}$ found that the overexpression of OCT-4 and Nanog promoted the formation of spheres with an increase of CD133 in lung adenocarcinoma. A similar process was detected in pancreatic cancer ${ }^{8}$ and colon cancer, ${ }^{13}$ both defined by SOX-2 and Lin-28B. Therefore, these transcription factors are also vital and necessary for the dedifferentiation process of tumors, thus inducing the formation of cancer stem-like cells.

In induced pluripotent stem cells (iPSCs), findings have revealed that the reprogramming efficiency significantly increased after hypoxia exposure, ${ }^{14}$ indicating that hypoxia has an important role in the dedifferentiation process. A tumor is an abnormal tissue in the body that grows without control. In addition, the proliferation rate of tumor cells is much faster than the formation of vessels, thus promoting the formation of a hypoxic microenvironment around tumor cells, including cancer stem cells and non-cancer stem cells (non-CSCs). ${ }^{15}$ Traditional studies have shown that hypoxia has a critical role in the stemness maintenance of CSCs. However, many researchers have ignored the influence of hypoxia on non-CSCs. Thus, to date, there have been few studies concentrated on nonCSCs influenced by hypoxia as a sole factor. In 2013, Li et al. ${ }^{15}$ found that unsorted glioma cells highly expressed SOX-2, OCT-4 and CD133 after hypoxia exposure, which is in accordance with a study carried by Blazek ${ }^{16}$ in 2007. However, these studies cultured unsorted tumor cells under hypoxia in a stem cell medium containing EGF and FGF2; thus, it was difficult to determine which types of cells (CSCs or non-CSCs) facilitated the expansion of CSCs. Moreover, EGF and FGF2, as growth factors, can promote the dedifferentiation process; ${ }^{17,18}$ thus, it is still not possible to determine the effects of hypoxia on non-CSCs. To rule out these factors, we sorted tumor cells at least three times and performed our experiments in DMEM/F12 medium with $1 \% \mathrm{FBS}$, and we have taken glioma, hepatoma and lung cancer into consideration and detected dedifferentiation under hypoxic conditions.

\section{RESULTS}

Hypoxia increased the expression of transcription factors and stem cell markers

Studies have shown that transcription factors such as SOX-2, OCT-4, KLF-4, Nanog and Lin-28A contribute to tumor cell dedifferentiation. ${ }^{7,8,10,11,13}$ Therefore, we first detected whether hypoxia promoted an increase in SOX-2, OCT-4, KLF-4, Nanog and Lin-28A expression at the mRNA and protein levels. 
First, RT-qPCR was used to detect mRNA after hypoxia exposure. We found that these transcription factors were not expressed under normoxic conditions $\left(21 \% \mathrm{O}_{2}\right)$ in sorted A549 cells but that the expression of these factors increased significantly in a time-dependent manner following hypoxia treatment for 3, 6, 9, 12 and $24 \mathrm{~h}$. In addition, the results showed that the peak expression of SOX-2 was after $12 \mathrm{~h}$ of the hypoxia treatment, but the highest expression of OCT-4, KLF-4, Nanog and Lin-28A was observed after $9 \mathrm{~h}$ of hypoxia (Figure 1a). The expression of CD133, a stem cell marker in A549 cells, also increased obviously under hypoxic conditions (Figure 1a). Similar results were observed in sorted GL261 (Supplementary Figure S1A) and HepG2 cells (Supplementary Figure S1B).

Second, the results of the western blot analysis showed that there was no expression of SOX-2, OCT-4, KLF-4, Nanog and Lin$28 \mathrm{~A}$ in sorted A549 cells under normoxic conditions. However, the expression increased remarkably in a time-dependent manner following hypoxia treatment for 12, 24, 48 and $72 \mathrm{~h}$ (Figures $1 \mathrm{~b}$ and c). In addition, the CD133 expression in sorted A549 cells also
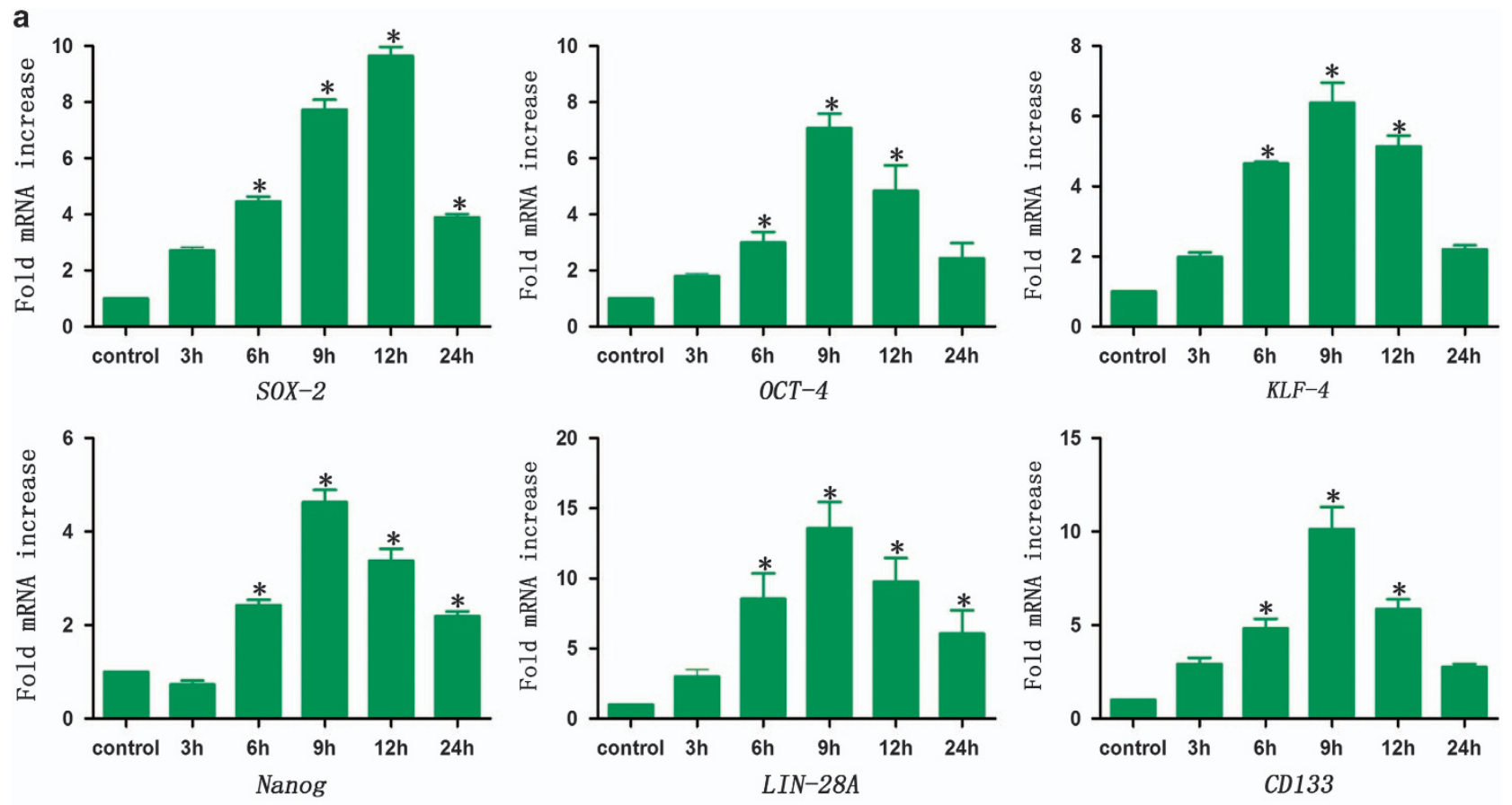

b

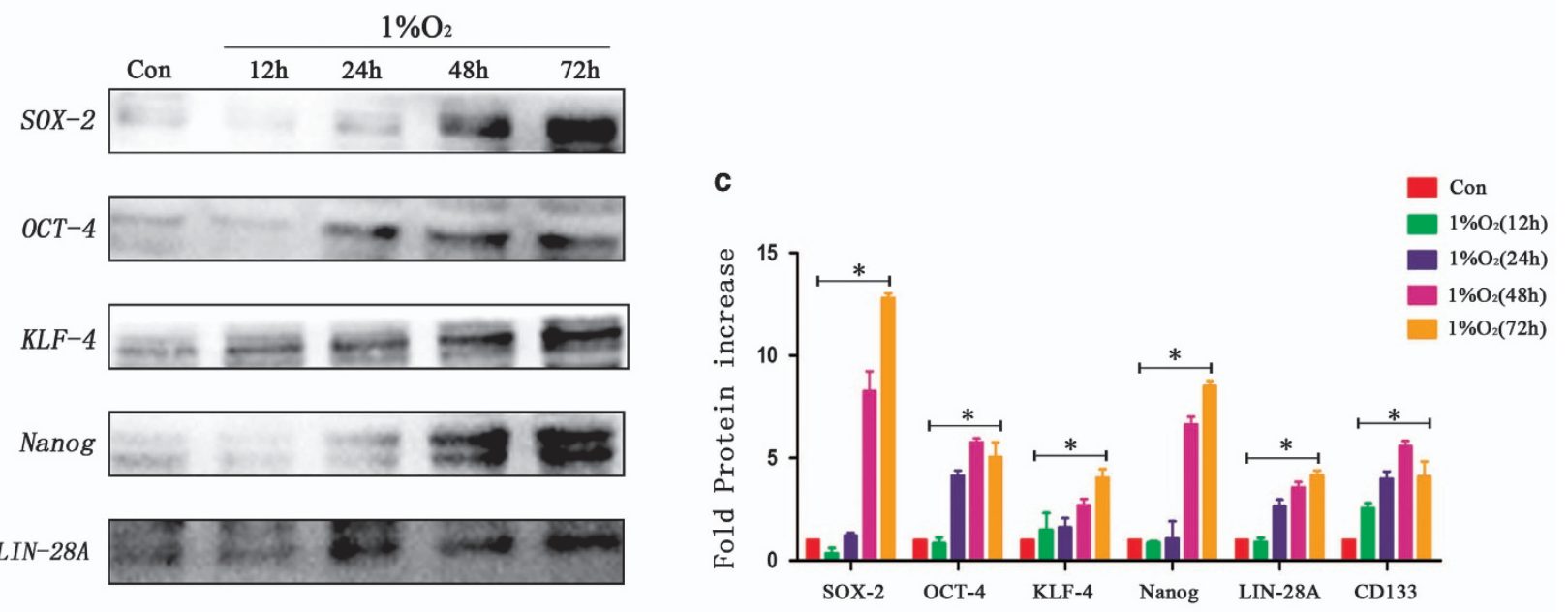

CD133

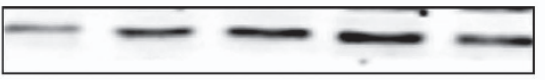

$\beta$-actin

Figure 1. Hypoxia promoted an increase in the expression of SOX-2, OCT-4, KLF-4, Nanog, Lin-28A and CD133. (a) The RT-qPCR analysis showed an upregulation in the expression of SOX-2, OCT-4, KLF-4, Nanog, Lin-28A and CD133 in a time-dependent manner in sorted A549 cells under hypoxic conditions $\left({ }^{*} P<0.05\right)$. For SOX-2, the peak expression was after $12 \mathrm{~h}$ of hypoxia, and the expression then decreased slightly but remained statistically higher than that of the control cells. The expression of OCT-4, KLF-4, Nanog Lin-28A and CD133 was highest after $9 \mathrm{~h}$ of hypoxia. (b, c) Western blot analysis showed that the transcription factors and stem cell markers were not expressed under normoxia. However, there was an increase in the expression of SOX-2, OCT-4, KLF-4, Nanog, Lin-28A and CD133 in a time-dependent manner after hypoxia treatment in sorted A549 cells $\left({ }^{*} P<0.05\right)$. 
increased after hypoxia exposure, and the peak expression was after $48 \mathrm{~h}$ of hypoxia. Similar results were identified in sorted GL261 (Supplementary Figure S2A) and HepG2 cells (Supplementary Figure S2B).

In addition to RT-qPCR and western blot analyses, we used immunofluorescence to detect the expression of stem cell markers after $48 \mathrm{~h}$ of hypoxia exposure. The results showed that both A549 and HepG2 cells highly expressed SOX-2, OCT-4, KLF-4, Nanog, Lin-28A and CD133 under hypoxic conditions (Figure 2).

\section{$\mathrm{A} 549\left(1 \% 0_{2}\right)$}
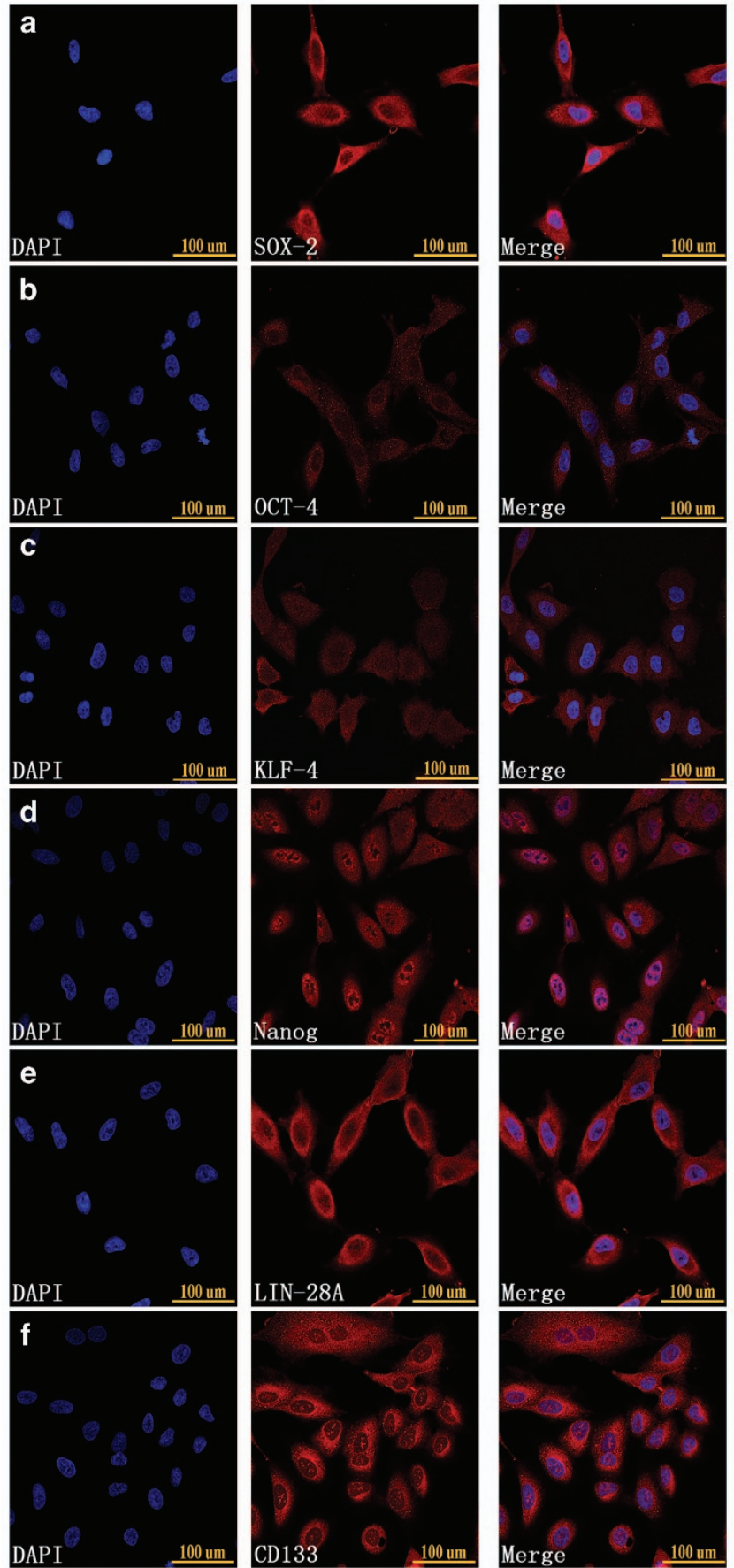

DAPI

100 un

CD133

$100 \mathrm{um}$

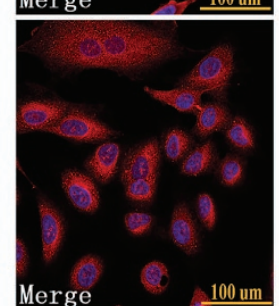

Hypoxia increased the expression of putative CSC markers

Next, we detected the changes in the expression of stem cell markers in sorted non-CSCs (GL261 CD133 $/$ CD15 ${ }^{-}$NESTIN $^{-}$cells, A549 $\mathrm{CD}_{133^{-}}$cells and HepG2 $\mathrm{CD}_{133^{-}}$cells) at 3, 6, 9, 12 and 15 days of hypoxia exposure by flow cytometry. In sorted A549 cells, the proportion of CD133-positive cells was only $5.59 \% \pm 2.272$ in the control cells, and this proportion began to increase in a timedependent manner after hypoxia exposure. After 15 days of hypoxia exposure, the rate of CD133-positive cells reached $49.2 \% \pm 3.125$

\section{HepG2 $\left(1 \% 0_{2}\right)$}
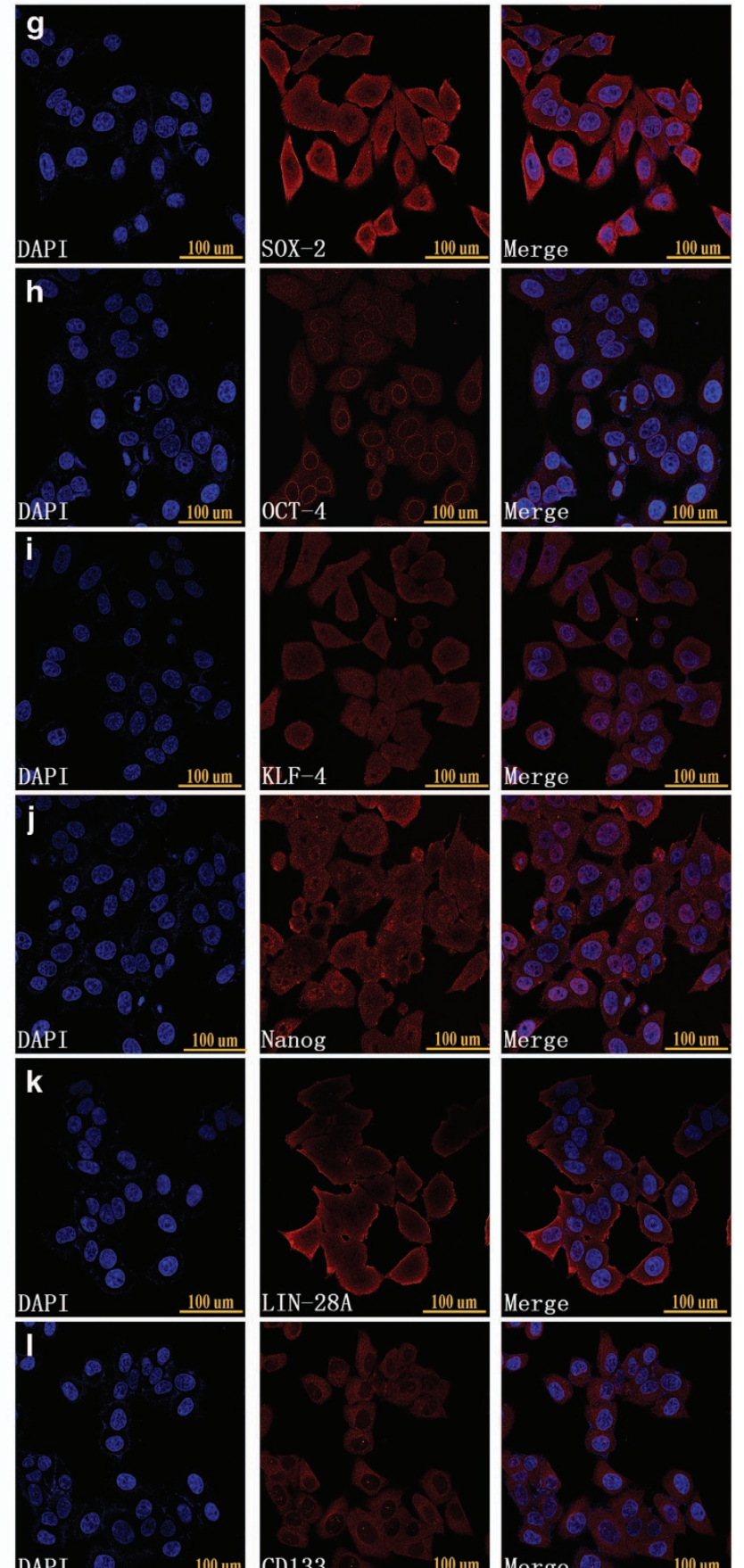

Figure 2. (a-f) Immunofluorescence staining showed that A549 CD133-negative cells highly expressed SOX-2, OCT-4, KLF-4, Nanog, Lin-28A and CD133 after $48 \mathrm{~h}$ of $1 \% \mathrm{O}_{2}$ exposure. (g-I) Immunofluorescence staining showed that HepG2 CD133-negative cells highly expressed SOX-2, OCT-4, KLF-4, Nanog, Lin-28A and CD133 after $48 \mathrm{~h}$ of $1 \% \mathrm{O}_{2}$ exposure. 
(Figure 3a). The same trend was observed in sorted HepG2 cells after hypoxia treatment (Figure 3a). For sorted GL261 cells, the proportion of CD133-positive cells was $7.03 \% \pm 3.425$ in the normoxia control group, and this rate increased remarkably from $20.3 \% \pm 2.547$ to $97.6 \% \pm 3.791$ at days 9 and 15 of hypoxia, respectively (Figure 3a), demonstrating that almost all the sorted GL261 cells after 15 days of hypoxia were CD133 positive. In addition, the results also showed that the expression of two other stem cell markers, CD15 and NESTIN, was upregulated, increasing from $0.56 \% \pm 0.251$ to $60.2 \% \pm 3.472$ and $3.96 \% \pm 5.231$ to $60.3 \% \pm 5.284$, respectively (Figure 3a). These data show that the proportion of stem cell markers in non-CSCs increased under hypoxic conditions (Figure 3b).

Sphere formation from a single sorted cancer cell was induced by hypoxia

As floating sphere-like proliferation is a basic feature of CSCs, ${ }^{19}$ it was necessary to investigate whether hypoxia induces sphere formation in sorted cells. The results showed that sorted A549, HepG2 and GL261 non-CSCs formed spheres under hypoxic conditions, and the rates at 21 days were over 50\% (sphere rate $=\mathrm{d} 21$ sphere number $/ \mathrm{d} 0$ seeded cells). However, under normoxic conditions $\left(21 \% \mathrm{O}_{2}\right)$, tumor cells only formed loose aggregates with a rate less than $5 \%$, and most of the cells were dead after the normoxia treatment (Figures $4 b$ and $c$ ).

Stem cell markers and asymmetric division detection for newly formed spheres

We used immunofluorescence to detect whether the newly formed spheres expressed stem cell markers, and the results showed that all the markers, including SOX-2, OCT-4, KLF-4, Nanog, Lin-28A, CD133, CD15 and NESTIN were highly expressed in the newly formed GL261 spheres (Figure 5a).
Asymmetric division as one of the most important features of stem cells. ${ }^{20}$ To evaluate whether these newly formed spheres exhibited this characteristic, we transferred these spheres to 24well plates and cultured them in either serum-free medium containing EGF and FGF2 (stem cell medium) or DMEM/F12+10\% FBS (differentiated cell medium). The results showed that these newly formed spheres exhibited self-renewal and extensive proliferation as suspension cells in the stem cell medium, but adherent growth and morphology was induced with 10\% FBS administration (Figure 5b).

Effect of hypoxia on the cell cycle and apoptosis

Cell cycle arrest and apoptosis resistance are CSC characteristics. ${ }^{15}$ We used flow cytometry to detect the influence of hypoxia on the cell cycle and apoptosis. The results showed that more cells were arrested in the $G_{0} / G_{1}$ phase and fewer cells were in the $G_{2} / M+S$ phase after 3 days of hypoxia treatment (Figures $6 a$ and $b$ ). In addition, we found that normoxia induced more cell apoptosis compared with hypoxia (Figures $6 \mathrm{c}$ and d). Besides, the newly formed spheres in hypoxia 14 days were also arrested in the $G_{0} / G_{1}$ phase (Supplementary Figure S2C). Both control cells and spheres originated under hypoxia were exposed to temozolomide $(100 \mu \mathrm{M})$ under normoxia conditions for $48 \mathrm{~h}$ followed by apoptosis detection through flow cytometry. Our results indicated that the cells from hypoxia-derived spheres showed reduced apoptosis compared with control normoxic cells after temozolomide treatment (Supplementary Figure S2D).

\section{DISCUSSION}

Dedifferentiation, as a biological phenomenon, exists in various systems, including muscle, ${ }^{21}$ monocytic $^{22}$ and spermatogonial ${ }^{23}$ cells, which suggests that stem-like cells with both the functional

a

\begin{tabular}{rcrrrrr}
\hline & $21 \% \mathrm{O}_{2}$ & $1 \% \mathrm{O}_{2}(3 \mathrm{~d})$ & $1 \% \mathrm{O}_{2}(6 \mathrm{~d})$ & $1 \% \mathrm{O}_{2}(9 \mathrm{~d})$ & $1 \% \mathrm{O}_{2}(12 \mathrm{~d})$ & $1 \% \mathrm{O}_{2}(15 \mathrm{~d})$ \\
\hline $\mathrm{A} 549 \mathrm{CD} 133$ & $5.59 \pm 2.272$ & $11.9 \pm 3.791$ & $13.4 \pm 3.652$ & $21.1 \pm 2.165$ & $23.1 \pm 2.342$ & $49.2 \pm 3.125$ \\
$\mathrm{H}$ HepG2 CD133 & $2.04 \pm 1.253$ & $4.30 \pm 1.823$ & $5.03 \pm 1.275$ & $6.76 \pm 2.329$ & $19.0 \pm 2.195$ & $40.6 \pm 2.871$ \\
$\mathrm{GL} 261 \mathrm{CD} 133$ & $7.03 \pm 3.425$ & $7.27 \pm 4.261$ & $12.2 \pm 3.982$ & $20.3 \pm 2.547$ & $96.8 \pm 5.672$ & $97.6 \pm 3.791$ \\
GL261 CD15 & $0.56 \pm 0.251$ & $1.06 \pm 0.327$ & $1.19 \pm 0.852$ & $1.76 \pm 0.127$ & $50.2 \pm 2.265$ & $60.2 \pm 3.472$ \\
GL261 NESTIN & $3.96 \pm 5.231$ & $30.8 \pm 4.297$ & $43.3 \pm 3.193$ & $48.4 \pm 4.251$ & $53.8 \pm 3.215$ & $60.3 \pm 5.284$ \\
\hline
\end{tabular}

b

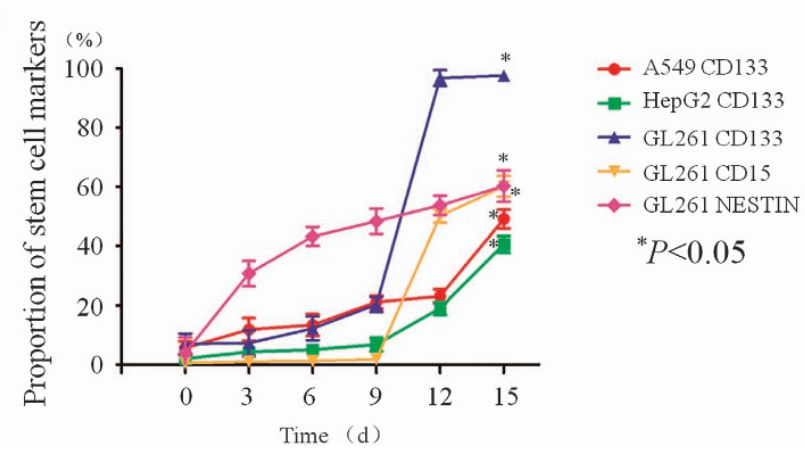

Figure 3. Hypoxia increased the expression of putative CSC markers. (a) In sorted A549 cells, the proportion of CD133-positive cells was only $5.59 \% \pm 2.272$ in the control cells, and this proportion increased in a time-dependent manner under hypoxic conditions. After 15 days of hypoxia, the proportion of CD133-positive cells reached $49.2 \% \pm 3.125$. The CD133 expression in sorted HepG2 cells also increased from $2.04 \% \pm 1.253$ to $40.6 \% \pm 2.871$ after 15 days of hypoxia. For GL261 cells, the proportion of CD133-positive cells was $7.03 \% \pm 3.425$ in the normoxia control cells, and this rate increased remarkably from 9 days to 15 days of hypoxia exposure from $20.3 \% \pm 2.547$ to $97.6 \% \pm 3.791$. In addition, the results also showed that the expression of two other stem cell markers, CD15 and NESTIN, was upregulated, increasing from $0.56 \% \pm 0.251$ to $60.2 \% \pm 3.472$ and $3.96 \% \pm 5.231$ to $60.3 \% \pm 5.284$, respectively, after 15 days of hypoxia. (b) The proportion of stem cell markers in sorted cells increased significantly under hypoxic conditions $\left({ }^{*} P<0.05\right)$. 


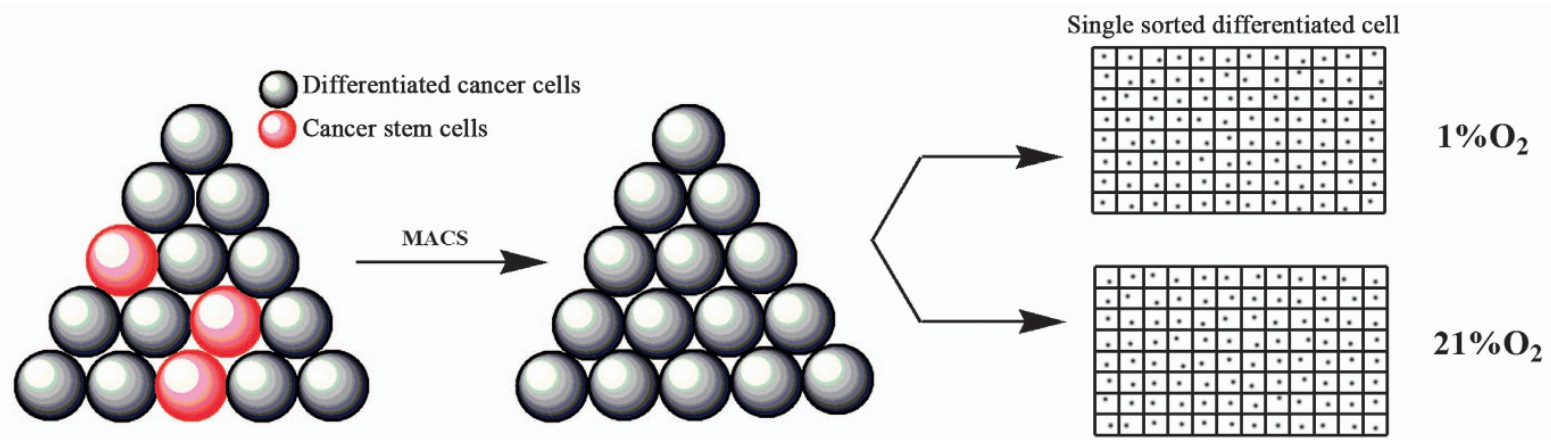

b
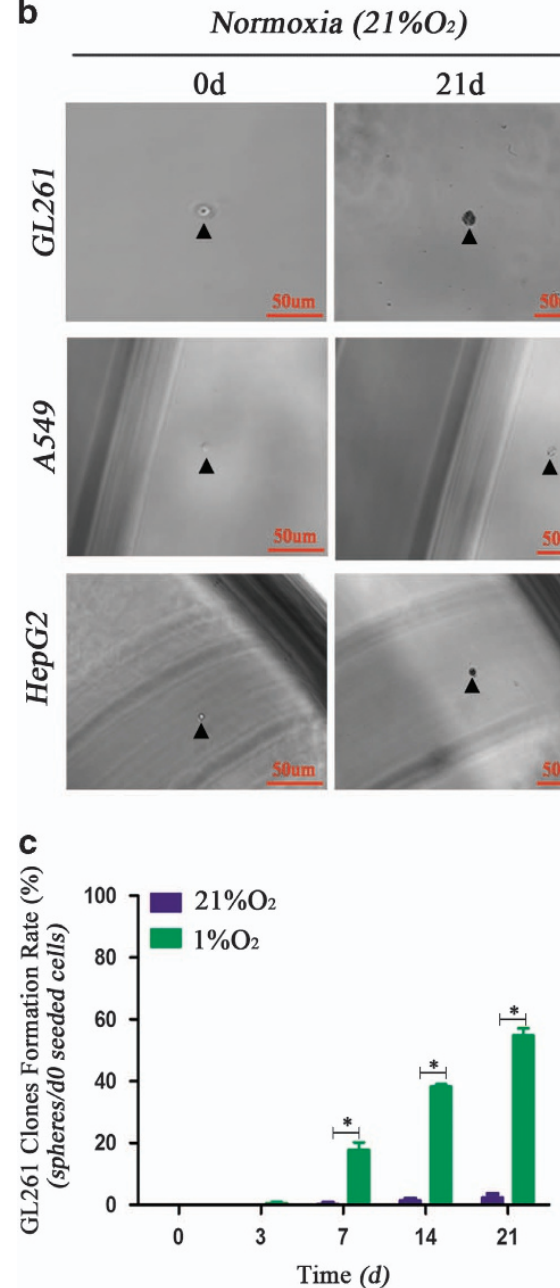

Hypoxia $\left(1 \% \mathrm{O}_{2}\right)$
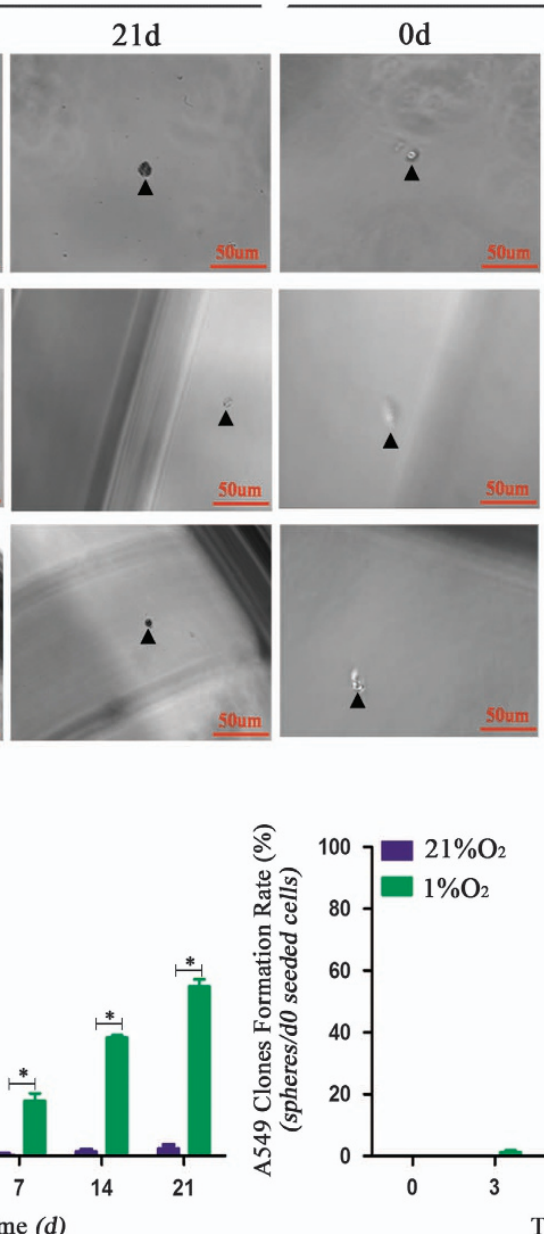

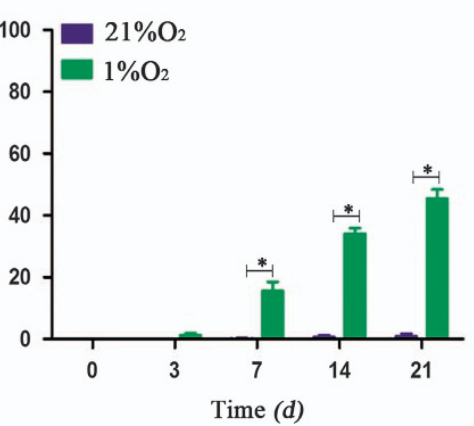

Figure 4. The spheres formed by single sorted cancer cells under hypoxia. (a) Single cancer cell seeding model; non-cancer stem cells were sorted using magnetic cell sorting, counted and diluted to 1500 cells/ $1 \mathrm{ml} \mathrm{DMEM} / \mathrm{F} 12+10 \% \mathrm{FBS}$, and then $1 \mu \mathrm{l}$ of the suspension was seeded into each well of $96-$ well plates containing $170 \mu \mathrm{l}$ of DMEM/F12 without serum. (b, c) Single sorted (CD133 ${ }^{-}$cells for A549 and HepG2, CD133 ${ }^{-}$CD15 ${ }^{-} \mathrm{NESTIN}^{-}$cells for GL261) cancer cells formed a sphere after 21 days of hypoxia exposure; however, the cells under normoxia were dead, and there was no sphere formation $(* P<0.05)$.

and morphological properties of stem cells can be induced from general tumor cells in some cases. ${ }^{24,25}$ In addition to normal tissues, some tumors such as glioma, lung adenocarcinoma, pancreatic cancer and breast cancer also exhibit dedifferentiation in some cases. ${ }^{26}$ In 2014, Auffinger et al. ${ }^{27}$ found that therapeutic doses of temozolomide (TMZ) consistently increased the expression of pluripotency markers of glioma stem cells (GSCs), including CD133, CD15, NESTIN, SOX-2 and OCT-4, which was observed as a reversion or dedifferentiation process from non-GSCs to GSCs. To further verify this result, they implanted glioma cells after TMZ treatment into nude mice, and more efficient grafting and invasive phenotype of cells were observed. Taken together, their findings suggested that glioma cells exposed to TMZ chemotherapeutic agents were able to interconvert between non-GSCs and GSCs through dedifferentiation and differentiation. This was in accordance with a study conducted by Dahan et al., ${ }^{28}$ which demonstrated that ionizing radiation treatment can induce the formation of GSCs through dedifferentiation, with an increase in the expression of stem cell markers such as CD133, SOX-2, NESTIN and Olig2 and a decrease in the expression of the differentiated 
markers GFAP and Tuj1. Moreover, the identified cancer cells after ionizing radiation treatment possessed a high ability to generate primary and secondary neurospheres with increased tumorigenicity. In addition, DNA damage inducers such as UV light and

a
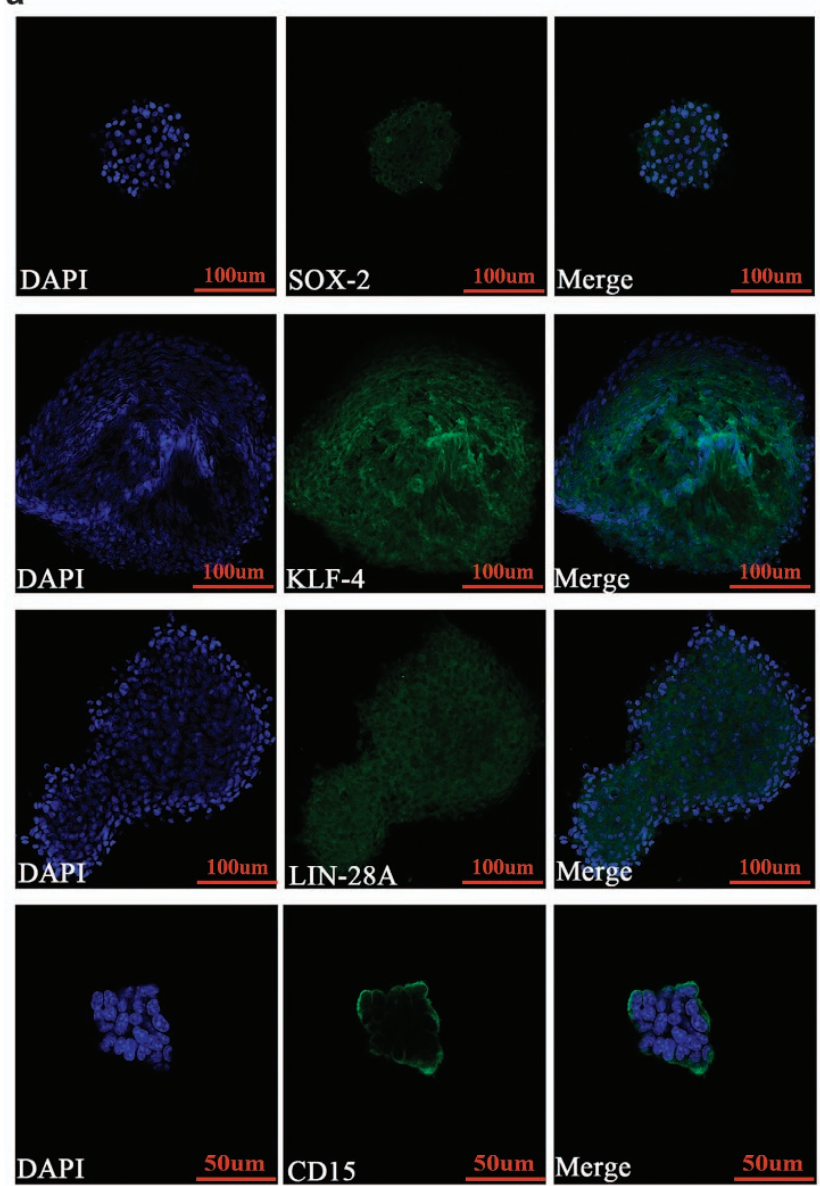

b

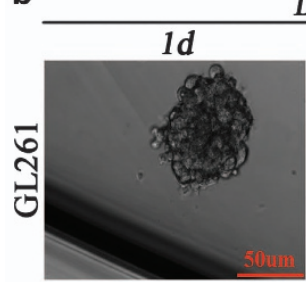

DMEM/F $12+10 \%$ FBS
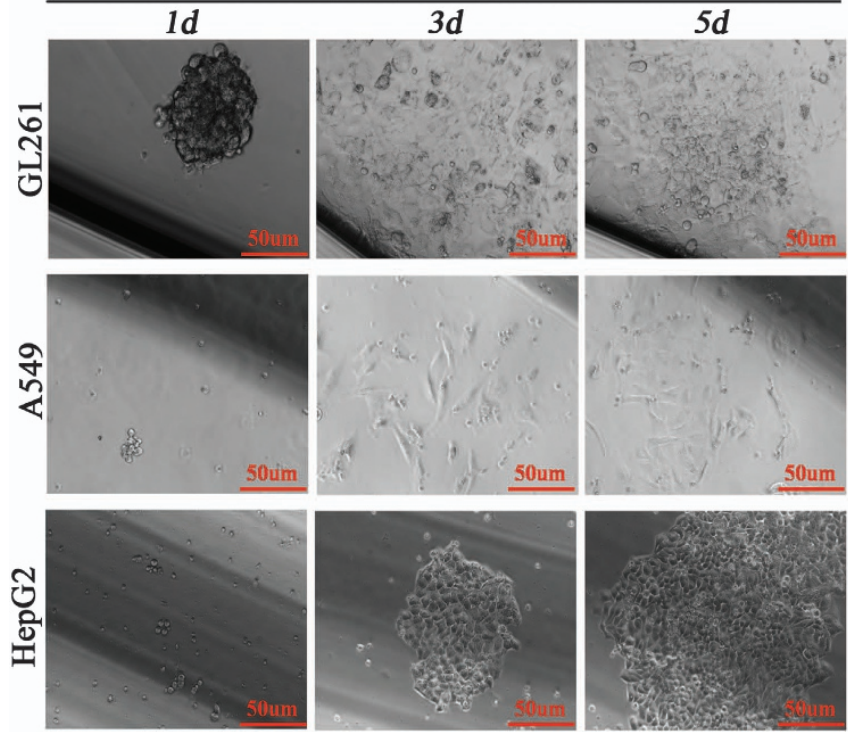

mitomycin $\mathrm{C}$ also increased the number of CSCs in NPC CNE-2 and neuroblastoma SKN-SH cells. ${ }^{29}$

Many studies have shown that transcription factors, such as SOX-2, OCT-4, KLF-4, Nanog and Lin-28A, have an important role
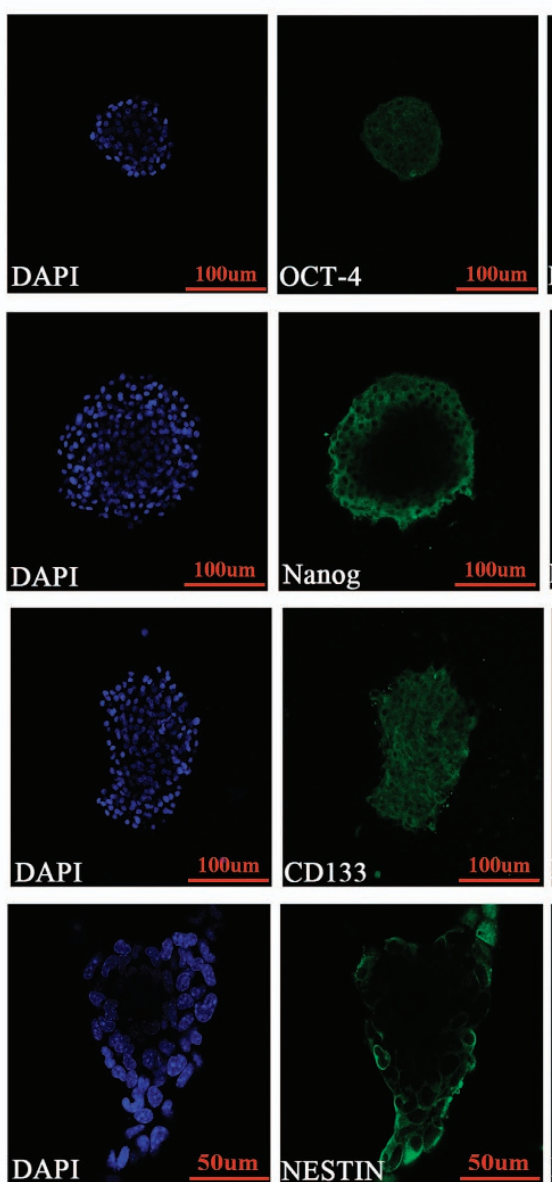

Merge
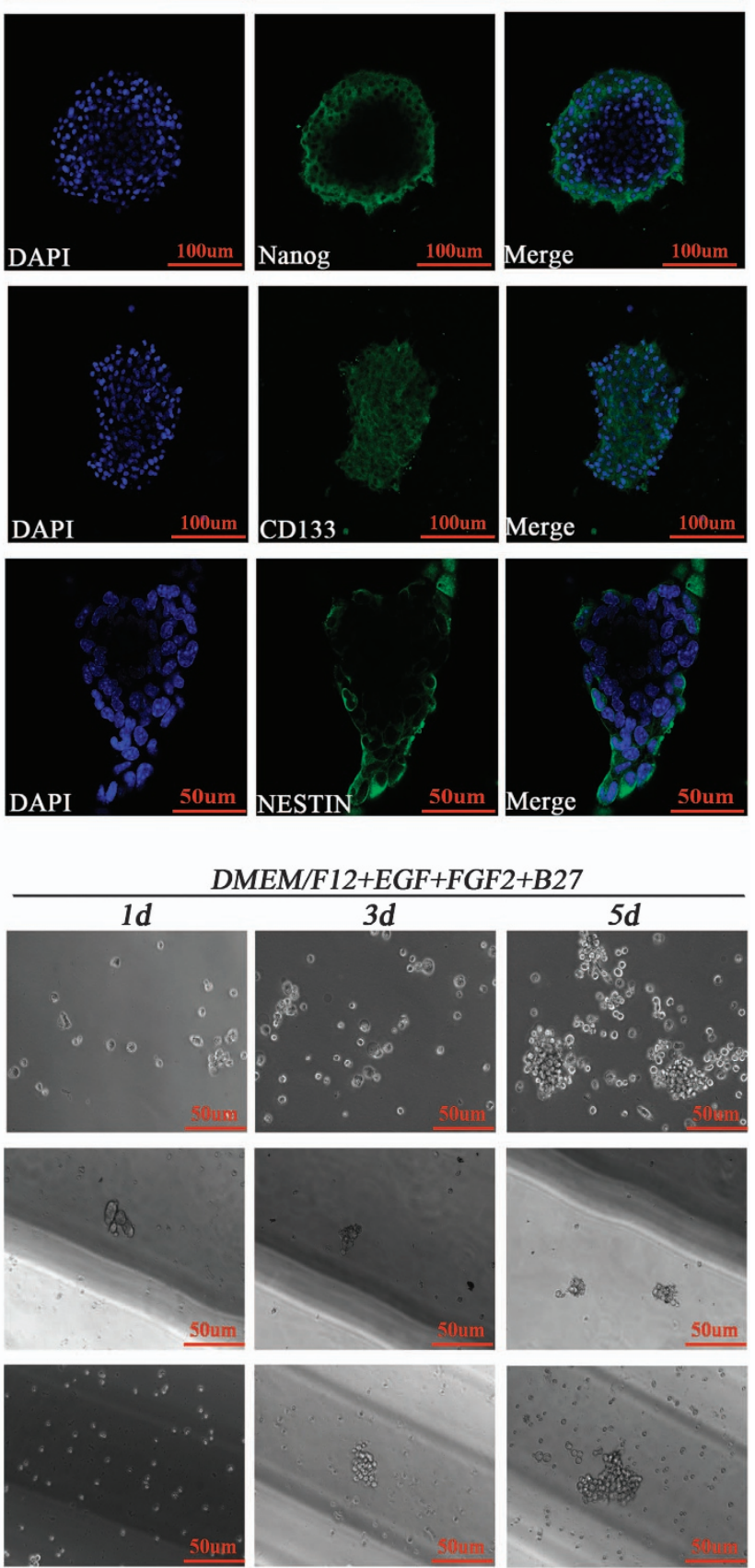

Figure 5. Newly formed spheres highly expressed transcription factors and showed asymmetric division. (a) Immunofluorescence staining showed that the newly formed GL261 spheres highly expressed SOX-2, OCT-4, KLF-4, Nanog, Lin-28A, CD133, CD15 and NESTIN. (b) These newly formed GL261 spheres kept growing in a suspension and proliferated extensively in stem cell culture medium (DMEM/F12+EGF+FGF2 + B27) but presented an adherent phenotype in differentiated medium (DMEM/F12+10\% FBS). 
in dedifferentiation or reprogramming processes. HerrerosVillanueva et $a l^{8}{ }^{8}$ reprogrammed SOX-2 in pancreatic cancer cells, and the results showed that reprogramming the cells promoted cell proliferation and contributed to stemness/dedifferentiation. This was in accordance with research by Chiou et al., ${ }^{11}$ whose study demonstrated that the co-expression of OCT-4 and Nanog
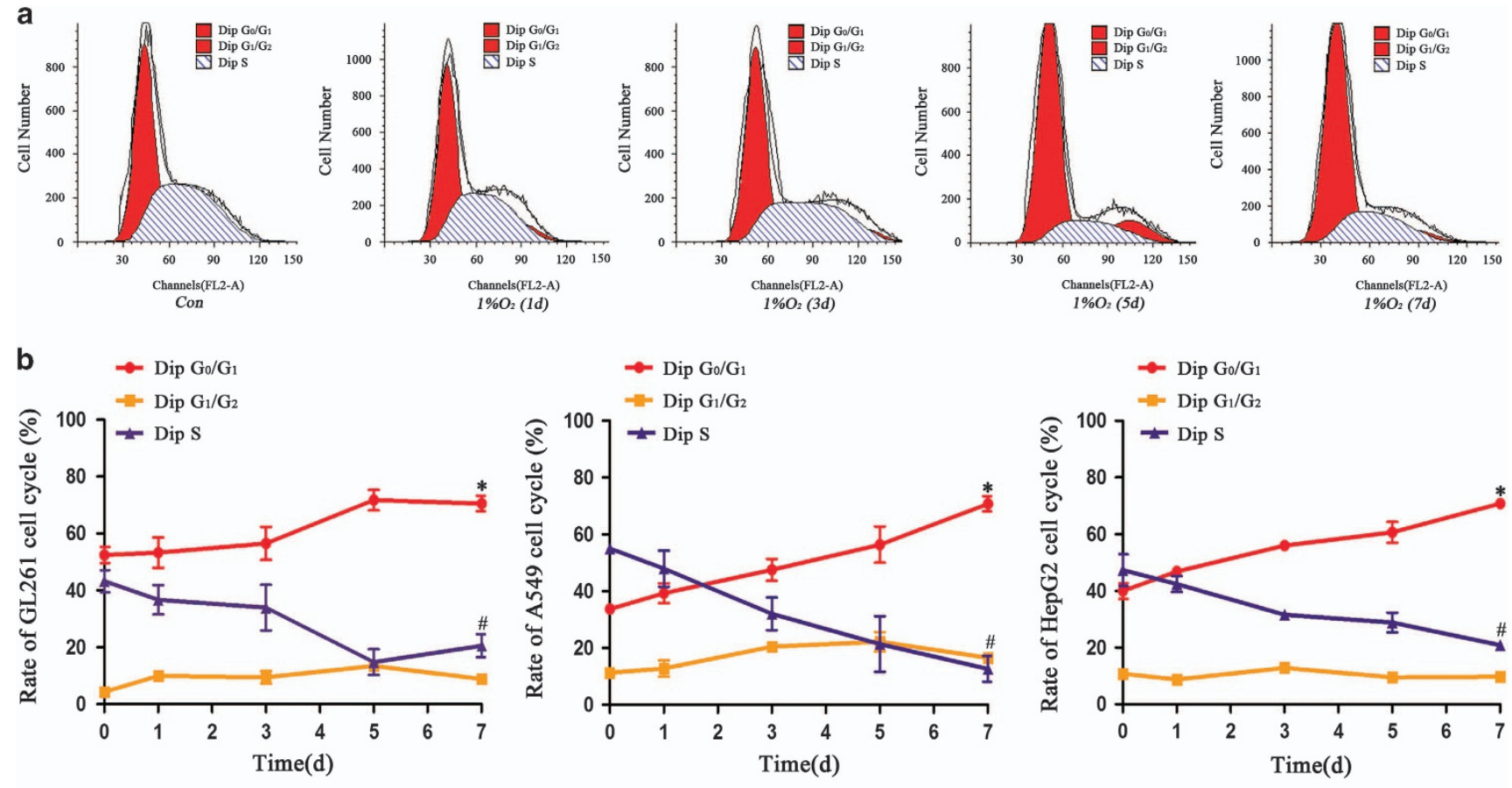

c
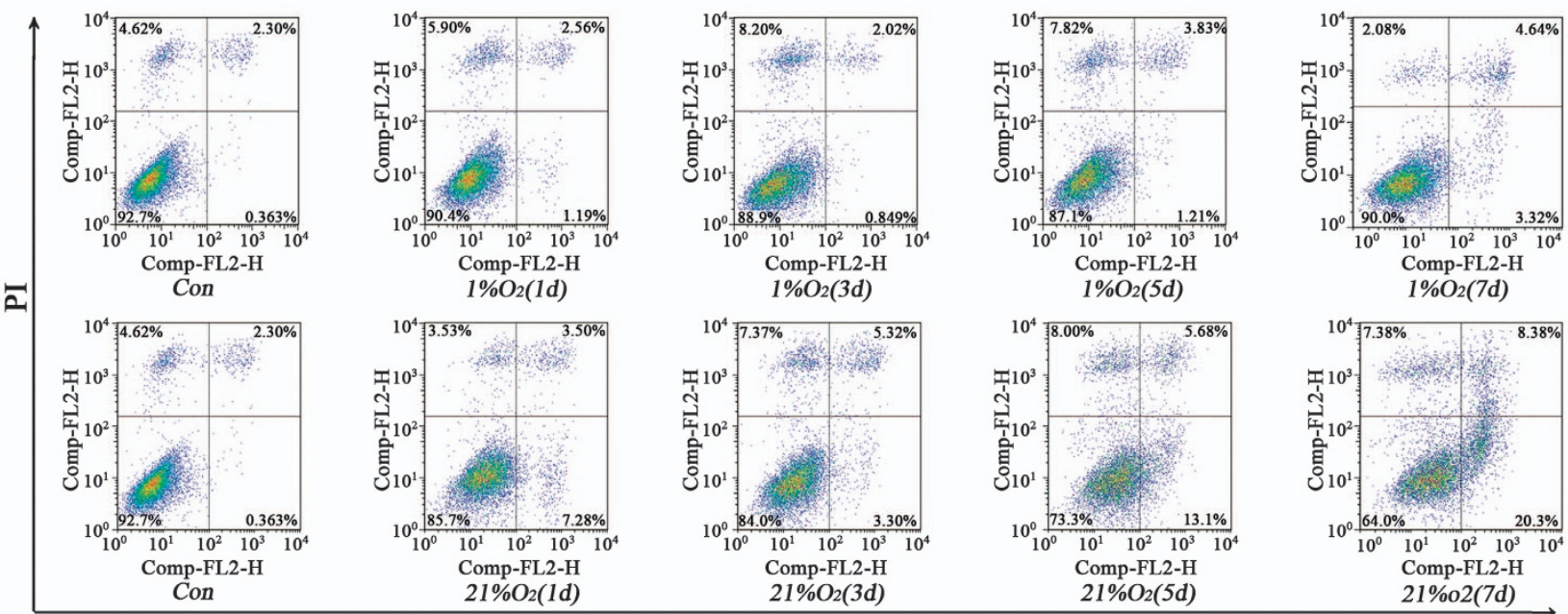

d
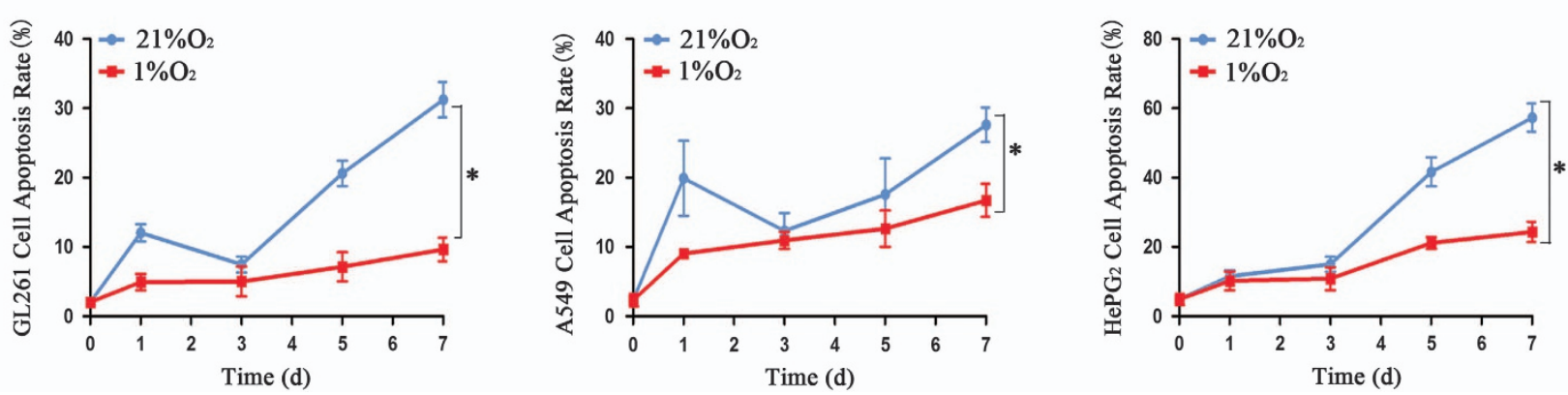

Figure 6. Cells under hypoxia showed cell cycle arrest and lower cell apoptosis. (a) A representative graph of the cell cycle arrest of sorted GL261 cells after hypoxia treatment. (b) Sorted GL261, A549 and HepG2 cells in hypoxia exhibited an increase in cells in the $G_{0} / G_{1}$ phase and a decrease in the proportion of cells in the $G_{1} / G_{2}$ and $S$ phase $\left({ }^{*} P<0.05\right.$, $\left.{ }^{\#} P<0.05\right)$. (c) Flow cytometry detected the apoptosis of sorted GL261 cells under hypoxia conditions. (d) The cell apoptosis rate was much higher in cells treated with normoxia than those treated with hypoxia ( ${ }^{*} P<0.05$ ) 
promoted the formation of cancer stem cell-like cells through dedifferentiation and enhanced malignancy in lung adenocarcinoma. A similar phenomenon was also detected in ovarian cancer recently, and this study showed that both primary and recurrent ovarian cancer highly expressed OCT-4A and that the knockdown of OCT-4A reduced cell proliferation, inhibited spheroid formation, suppressed stem cell marker expression, prolonged the survival time of xenograft mice and reduced tumor size. ${ }^{30}$ Other tumors such as glioma, ${ }^{7}$ colon cancer $^{13}$ and melanoma ${ }^{31,32}$ cells also exhibit this phenomenon when reprogrammed by defined transcription factors. On the basis of these studies, we conclude that SOX-2, OCT-4, KLF-4, Nanog and Lin-28A contribute greatly to the events of dedifferentiation.

Hypoxia as a physiological phenomenon exists in tumors. ${ }^{33,34}$ Although a few studies have paid attention to the influence of hypoxia on unsorted cancer cells, ${ }^{15,16,35,36}$ these studies could not identify the role of hypoxia on non-CSCs, because the increased expression of CD133, SOX-2 or OCT-4 under hypoxia may be from CSCs themselves. In addition, almost all the traditional studies used cancer cells cultured in stem cell medium containing EGF, FGF2 or IGF-1. ${ }^{35}$ This introduced another question of whether the increased expression of stem cells may be induced by the stimulation of EGF, FGF2 and IGF-1 and not hypoxia. To avoid these problems, we sorted CD133- cells (A549, HepG2) or CD133-/ CD15 ${ }^{-}$NESTIN ${ }^{-}$cells (GL261) by MACS three times and cultured cells in DMEM/F12 medium without EGF, FGF2 or IGF-1. In our study, we think the most important and powerful result was the sphere formation by a single sorted cancer cell. The results showed that compared with the control cells under normoxic conditions, the sphere formation rate under hypoxia by a single cell was much higher than the proportion of CSCs in the glioma, lung cancer and hepatoma cells. Though some newly formed spheres in our study may come from CSCs, we think that a subset of spheres must come from some non-CSCs. To verify our results, we detected the expression of SOX-2, OCT-4, KLF-4, Nanog and Lin-28A under hypoxia and found that hypoxia promoted the expression of these factors remarkably. At the same time, we also demonstrated that CD133 expression increased significantly after hypoxia treatment in glioma, lung cancer and hepatoma cell lines. In addition, we found that these newly formed spheres exhibited asymmetric division, cell cycle arrest ${ }^{15,37}$ and a lower apoptosis rate, ${ }^{38}$ which was in accordance with the basic features of CSCs. Therefore, according to our in vitro results, we can conclude that cancer stem cells can be induced through dedifferentiation in glioma, lung cancer and hepatoma under hypoxia conditions. The existence of dedifferentiation shows us that there exists an interchange between non-CSCs and CSCs, which promote cancer to become more malignant; thus, we should take the dedifferentiation process into consideration in developing cancer treatments. However, the molecular mechanism of this dedifferentiation phenomenon under hypoxic conditions needs further study, and we speculate that SOX-2, OCT-4, KLF-4, Nanog and Lin-28A may have an important role in this process, based on traditional studies regarding the formation of iPS cells by these defined factors and the influences of these factors on tumors.

In summary, this study showed that cancer stem-like cells can be induced through dedifferentiation under hypoxic conditions in glioma, hepatoma and lung cancer, which provides a new theory of tumor development, recurrence and resistance to chemo- and radiotherapy. Hence, we should take non-CSCs and the hypoxic microenvironment into consideration when developing tumor treatments.

\section{MATERIALS AND METHODS}

\section{Cell culture and non-CSCs isolation}

The GL261, A549 and HepG2 cell lines were bought from ATCC. The GL261 cells were cultured in DMEM/F12+10\% fetal bovine serum (FBS), and the A549 and HepG2 cells were cultured in DMEM+10\% FBS. CD133, CD15 and NESTIN were considered glioma stem cell markers and were used to sort CD $133^{-}$CD $15^{-}$NESTIN ${ }^{-}$GL261 cells as non-GSCs. For A549 and HepG2 cells, we considered CD133 to be a stem cell marker and sorted $\mathrm{CD} 133^{-}$cells by magnetic cell sorting (MACS). The $\mathrm{CD}_{133^{+}}$immune magnetic bead separation kits were bought from Miltenyi Biotech, Bergisch-Gladbach, Germany. First, we collected cancer cells cultured under normoxia for 3 days in DMEM/F12+10\% FBS at $37^{\circ} \mathrm{C}$, and we then used $0.25 \%$ trypsin to digest the cancer cells and obtain a cell suspension. Next, PBS containing $0.5 \%$ BSA and 0.08\% EDTA (PBSE; $10^{8}$ cells $/ 500 \mu \mathrm{l}$ ) was used to re-suspend the cancer cells, and the cells were then incubated at $4{ }^{\circ} \mathrm{C}$ for 15 min with CD133 $3^{+}$IgGs (Miltenyi Biotech). Then, we centrifuged the cell suspension again and re-suspended cells in PBSE $\left(10^{8}\right.$ cells $\left./ 300 \mu \mathrm{l}\right)$ and labeled the cells with IgG MicroBeads (Miltenyi Biotech) for $15 \mathrm{~min}$ at $10^{\circ} \mathrm{C}$. We next centrifuged the cell suspension and washed and re-suspended cells in PBSE. The miniMACS magnet was fixed on the MACS multistand, and $500 \mu$ PBSE was used to flush the cell separation column. Finally, the cell suspension was poured into the column reservoir, and we collected the unlabeled nonmagnetic cells as CD133cells. To increase the purity of the $\mathrm{CD} 133^{-}$cells, we repeated the above steps at least three times. Sorted A549 and HepG2 $\mathrm{CD}_{133^{-}}$cells were cultured in DMEM+10\% FBS. For GL261 cells, we used a similar method to isolate the $\mathrm{CD}_{133^{-}} / \mathrm{CD} 15^{-} / \mathrm{NESTIN}^{-}$cells and cultured them in DMEM/F12+10\% FBS. All sorted cells were used within 1 week, and we sorted the non-CSCs again if these cells had been cultured for more than 7 days.

Real-time quantitative PCR

Sorted GL261, A549 and HepG2 cells were cultured under hypoxia for 0, 3, $6,9,12$ and $24 \mathrm{~h}$; we then collected the cells and analyzed the expression of stem cell markers at the mRNA level. Total mRNA was extracted from the cells, and the expression of CD133, SOX-2, KLF-4, OCT-4, Nanog, Lin-28A, CD15 and NESTIN was examined by real-time quantitative PCR (RT-qPCR). The reactions were performed with an initial denaturation at $94{ }^{\circ} \mathrm{C}$ for 5 min, followed by 40 cycles of denaturation at $94^{\circ} \mathrm{C}$ for $30 \mathrm{~s}$, annealing at $57^{\circ} \mathrm{C}$ for $30 \mathrm{~s}$, and extension at $72{ }^{\circ} \mathrm{C}$ for $30 \mathrm{~s}$. The primer sequences were as follows:

Upstream $\left(5^{\prime} \rightarrow 3^{\prime}\right) \quad$ Downstream $\left(5^{\prime} \rightarrow 3^{\prime}\right)$

Human OCT-4 $\quad$ GAGAG

GAGTTCTGTGG

Human KLF-4 GGCTGCGGCAAAACCTA- CGGGCGAATTCCATCCAC CAC

Human Nanog CCGCGCCCTGCCTAGAAAA- AGCCTCCCAATCCCAAAGAC CAATACG

Human CD133 GCCCCCAGGAAATTGAG- GCTTGGTATAGAGTGCTGAAC

Human Lin-28A GGCGGGAGGGTAGGAAAGC

Mouse SOX-2 GGGGGCAGCGGCGTAAGATG

Mouse OCT-4 GCCCGGAAGAGAAAGCGAAC

Mouse KLF-4 CCGGCCCAACACACACGACTTC CAGTGATTG CAGCAAAATCAACCATCAAATAAAC CCCGCTCGCCATGCTGTTC

GGGGCAGAGGAAAGGATACAG GAACCCGGTGGCATGAGCTCTTG

Mouse Nanog GCCCAGCTGTGTGCACTCAAGG GGCTTCCAGATGCGTTCACCAGATA

Mouse Lin-28A GGGGTGGGGAGTाTCGT- GGGGAGAGGGAGACAATACATG GAAACCAAG

Mouse CD133 CCGCGATGGACTCTGCTGT- GGGCACAGTCTCAATAATG CATCGTCGTATAC

Mouse CD15 ATCGGGCTGCTGCACACTG AGCGGAAGTAGCGGCGATAGAC

Mouse NESTIN GCCCAAGCAGGTGAACAA- CAGCCCTTGCATTCCAGACT

$\beta$-Actin ACCCGCCGCCAGCTCACC
GAGTCT

GGGGGGCACGAAGGCTCATC 
Western blot analysis of stem cell markers

Proteins were collected from sorted cells after hypoxia exposure for 0,12 , 24,48 and $72 \mathrm{~h}$. We then subjected the proteins to SDS-PAGE and transferred them to nitrocellulose membranes, which were blocked with $5 \%$ non-fat milk and incubated with primary antibodies against CD133 ( $1: 1000$, MBS462020, MyBiosource, San Diego, CA, USA), SOX-2 (1: 1000, MAB2018, R\&D Systems, Minneapolis, MN, USA), KLF-4 (1:1000, Human: AF3640; Mouse: AF3158 R\&D Systems), OCT-4 (1:1000, MAB1759, R\&D Systems), Nanog (1 : 1000, Human: AF1997; Mouse: AF2729 R\&D Systems), Lin-28A (1 : 1000, NBP1-49537, Novus Biologicals, Littleton, CO, USA), CD15 ( $1: 1000$, MAB2155, R\&D Systems) or NESTIN ( $1: 1000$, MAB2736, R\&D Systems). $\beta$-Actin was used as an internal control.

\section{Stem cell marker detection by immunofluorescence}

Sorted cells were cultured under hypoxia for $48 \mathrm{~h}$ to detect the expression of CD133, SOX-2, OCT-4, Lin-28A, KLF-4, Nanog, CD15 and NESTIN. The sorted cell lines were exposed to hypoxia for $48 \mathrm{~h}$, and $4 \%$ paraformaldehyde was used to fix the cells at $4{ }^{\circ} \mathrm{C}$ for $10 \mathrm{~min}$. The cells were washed with PBS, and $10 \%$ serum in PBS containing $0.5 \%$ Triton X-100 was used to block the cells. The cells were then incubated for $24 \mathrm{~h}$ at $4{ }^{\circ} \mathrm{C}$ with primary antibodies against CD133 (1:150, MBS462020, MyBiosource, San Diego, CA, USA), SOX-2 (1: 100, MAB2018, R\&D Systems), KLF-4 (1 : 100, Human: AF3640; Mouse: AF3158; R\&D Systems), OCT-4 (1:100, MAB1759 R\&D Systems), Nanog (1: 100, Human: AF1997; Mouse: AF2729 R\&D Systems), Lin-28A (1: 100, NBP1-49537, Novus Biologicals), CD15 (1 : 100, MAB2155, R\&D Systems) or NESTIN (1:100, MAB2736, R\&D Systems). The cells were then washed with PBS three times. Appropriate fluorophore-labeled secondary antibodies were added to the cells and incubated at $37^{\circ} \mathrm{C}$ for $1 \mathrm{~h}$. Images were acquired with a laser scanning confocal microscope (LSM780, ZEISS, Jena, Thuringia, Germany).

\section{Flow cytometric analysis}

CD133, as a cancer stem cell marker, was detected in GL261, A549 and HepG2 cells under hypoxia by flow cytometry. Because of the query of CD133 as a glioma stem cell marker, we also detected the proportion of CD15- and NESTIN-positive GL261 cells after hypoxia exposure. Sorted cells were exposed to hypoxia for $0,3,6,9,12$ and 15 days, then collected and incubated with an anti-CD133 antibody (Human: Miltenyi Biotech; Mouse: BioLegend, San Diego, CA, USA), anti-CD15 antibody (FAB2155G-100, R\&D Systems) and anti-NESTIN antibody (IC2736P, R\&D Systems) and analyzed with FCM. We also used flow cytometry to detect cell cycle arrest and apoptosis in the sorted cells under hypoxia exposure for 0, 1, 3, 5 and 7 days. Besides, spheres formed in hypoxia environment were also analyzed cell cycle; and cell apoptosis of the newly formed spheres was analyzed after temozolomide $(100 \mu \mathrm{M})$ treatment in normoxia.

Clonogenicity and asymmetric division assays

Sorted cells were digested with $0.25 \%$ trypsin, centrifuged and then suspended in DMEM/F12+10\% FBS. We then counted and diluted the cells to 1500 cells $/ 1 \mathrm{ml} \mathrm{DMEM} / \mathrm{F} 12+10 \% \mathrm{FBS}$, and $1 \mu \mathrm{l}$ of the mixed medium was added to each well of 96-well plates containing $170 \mu \mathrm{l}$ serum-free DMEM/ F12 medium. Six 96-well plates were grouped randomly into two groups; one group was incubated at $37^{\circ} \mathrm{C}$ with $1 \% \mathrm{O}_{2}$ and $5 \% \mathrm{CO}_{2}$ and another was incubated at $37{ }^{\circ} \mathrm{C}$ with $21 \% \mathrm{O}_{2}$ and $5 \% \mathrm{CO}_{2}$ (Figure $4 \mathrm{a}$ ). We observed, imaged and recorded the cell growth state at $0,3,7,14$ and 21 days. The newly formed spheres were centrifuged, and half of them were cultured with stem cell medium (DMEM/F12+EGF+FGF2+B27) and the others were incubated with differentiation culture medium (DMEM/F12+10\% FBS). Both groups of spheres were cultured at $37{ }^{\circ} \mathrm{C}$ with $21 \% \mathrm{O}_{2}$ and $5 \% \mathrm{CO}_{2}$ and the cell state was recorded at day 1,3 and 5 .

\section{Statistical analysis}

SPSS 19.0 was used for the statistical analysis, and the data were presented as the mean \pm standard deviation. The differences between cells cultured in hypoxia and normoxia were evaluated with a one-sample $t$-test or paired-samples $t$-test. A $P$-value less than 0.05 was considered statistically significant.

\section{ACKNOWLEDGEMENTS}

This study was funded by the National Natural Science Foundation of China (NSFC 81272784; 81672493) and the Science Foundation of Southwest Hospital (SWH2015QN10).

\section{COMPETING INTEREST}

The authors declare no conflict of interest.

\section{REFERENCES}

1 Takahashi K, Tanabe K, Ohnuki M, Narita M, Ichisaka T, Tomoda K et al. Induction of pluripotent stem cells from adult human fibroblasts by defined factors. Cell 2007; 131: 861-872.

2 Qian L, Huang Y, Spencer Cl, Foley A, Vedantham V, Liu L et al. In vivo reprogramming of murine cardiac fibroblasts into induced cardiomyocytes. Nature 2012; 485: 593-598.

3 Riddell J, Gazit R, Garrison BS, Guo G, Saadatpour A, Mandal PK et al. Reprogramming committed murine blood cells to induced hematopoietic stem cells with defined factors. Cell 2014; 157: 549-564.

4 Lee HK, Morin P, Wells J, Hanlon EB, Xia W. Induced pluripotent stem cells (iPSCs) derived from frontotemporal dementia patient's peripheral blood mononuclear cells. Stem Cell Res 2015; 15: 325-327.

5 Pointer KB, Clark PA, Zorniak M, Alrfaei BM, Kuo JS. Glioblastoma cancer stem cells: biomarker and therapeutic advances. Neurochem Int 2014; 71: 1-7.

6 Pacini N, Borziani F. Cancer stem cell theory and the Warburg effect, two sides of the same coin? Int J Mol Sci 2014; 15: 8893-8930.

7 Berezovsky AD, Poisson LM, Cherba D, Webb CP, Transou AD, Lemke NW et al. Sox2 promotes malignancy in glioblastoma by regulating plasticity and astrocytic differentiation. Neoplasia 2014; 16: 193-206, 206 e119-e125.

8 Herreros-Villanueva M, Zhang JS, Koenig A, Abel EV, Smyrk TC, Bamlet WR et al. SOX2 promotes dedifferentiation and imparts stem cell-like features to pancreatic cancer cells. Oncogenesis 2013; 2: e61.

9 Herreros-Villanueva M, Bujanda L, Billadeau DD, Zhang JS. Embryonic stem cell factors and pancreatic cancer. World J Gastroenterol 2014; 20: 2247-2254.

10 Wang D, Lu P, Zhang H, Luo M, Zhang X, Wei X et al. Oct-4 and Nanog promote the epithelial-mesenchymal transition of breast cancer stem cells and are associated with poor prognosis in breast cancer patients. Oncotarget 2014; 5: 10803-10815.

11 Chiou SH, Wang ML, Chou YT, Chen CJ, Hong CF, Hsieh WJ et al. Coexpression of Oct4 and Nanog enhances malignancy in lung adenocarcinoma by inducing cancer stem cell-like properties and epithelial-mesenchymal transdifferentiation. Cancer Res 2010; 70: 10433-10444.

12 Shan J, Shen J, Liu L, Xia F, Xu C, Duan G et al. Nanog regulates self-renewal of cancer stem cells through the insulin-like growth factor pathway in human hepatocellular carcinoma. Hepatology 2012; 56: 1004-1014.

13 King CE, Cuatrecasas M, Castells A, Sepulveda AR, Lee JS, Rustgi AK. LIN28B promotes colon cancer progression and metastasis. Cancer Res 2011; 71: 4260-4268.

14 Yoshida Y, Takahashi K, Okita K, Ichisaka T, Yamanaka S. Hypoxia enhances the generation of induced pluripotent stem cells. Cell Stem Cell 2009; 5: 237-241.

15 Li P, Zhou C, Xu L, Xiao H. Hypoxia enhances stemness of cancer stem cells in glioblastoma: an in vitro study. Int J Med Sci 2013; 10: 399-407.

16 Blazek ER, Foutch JL, Maki G. Daoy medulloblastoma cells that express CD133 are radioresistant relative to $\mathrm{CD} 133$ - cells, and the $\mathrm{CD} 133+$ sector is enlarged by hypoxia. Int J Radiat Oncol Biol Phys 2007; 67: 1-5.

17 Wan J, Ramachandran R, Goldman D. HB-EGF is necessary and sufficient for Müller glia dedifferentiation and retina regeneration. Dev Cell 2012; 22: 334-347.

18 Fessler E, Borovski T, Medema JP. Endothelial cells induce cancer stem cell features in differentiated glioblastoma cells via bFGF. Mol Cancer 2015; 14: 157.

19 Bar EE, Lin A, Mahairaki V, Matsui W, Eberhart CG. Hypoxia increases the expression of stem-cell markers and promotes clonogenicity in glioblastoma neurospheres. Am J Pathol 2010; 177: 1491-1502.

20 Gao X, McDonald JT, Hlatky L, Enderling H. Acute and fractionated irradiation differentially modulate glioma stem cell division kinetics. Cancer Res 2013; 73: 1481-1490.

21 Nguyen HT, Medford RM, Nadal-Ginard B. Reversibility of muscle differentiation in the absence of commitment: analysis of a myogenic cell line temperaturesensitive for commitment. Cell 1983; 34: 281-293.

22 Selle A, Ullrich O, Harnacke K, Hass R. Retrodifferentiation and rejuvenation of senescent monocytic cells requires PARP-1. Exp Gerontol 2007; 42: 554-562.

23 Brawley C, Matunis E. Regeneration of male germline stem cells by spermatogonial dedifferentiation in vivo. Science 2004; 304: 1331-1334. 
24 Olmez I, Shen W, McDonald H, Ozpolat B. Dedifferentiation of patient-derived glioblastoma multiforme cell lines results in a cancer stem cell-like state with mitogen-independent growth. J Cell Mol Med 2015; 19: 1262-1272.

25 Ostrakhovitch EA, Akakura S, Sanokawa-Akakura R, Goodwin S, Tabibzadeh S. Dedifferentiation of cancer cells following recovery from a potentially lethal damage is mediated by H2S-Nampt. Exp Cell Res 2015; 330: 135-150.

26 Friedmann-Morvinski $D$, Verma IM. Dedifferentiation and reprogramming: origins of cancer stem cells. EMBO Rep 2014; 15: 244-253.

27 Auffinger B, Tobias AL, Han Y, Lee G, Guo D, Dey M et al. Conversion of differentiated cancer cells into cancer stem-like cells in a glioblastoma model after primary chemotherapy. Cell Death Differ 2014; 21: 1119-1131.

28 Dahan P, Martinez Gala J, Delmas C, Monferran S, Malric L, Zentkowski D et al. lonizing radiations sustain glioblastoma cell dedifferentiation to a stem-like phenotype through survivin: possible involvement in radioresistance. Cell Death Dis 2014; 5: e1543.

29 Liang Y, Zhong Z, Huang Y, Deng W, Cao J, Tsao G et al. Stem-like cancer cells are inducible by increasing genomic instability in cancer cells. J Biol Chem 2010; 285: 4931-4940.

30 Samardzija C, Luwor RB, Volchek M, Quinn MA, Findlay JK, Ahmed N. A critical role of Oct4A in mediating metastasis and disease-free survival in a mouse model of ovarian cancer. Mol Cancer 2015; 14: 152.

31 Kumar SM, Liu S, Lu H, Zhang H, Zhang PJ, Gimotty PA et al. Acquired cancer stem cell phenotypes through Oct4-mediated dedifferentiation. Oncogene 2012; 31: 4898-4911.

32 Borrull A, Ghislin S, Deshayes F, Lauriol J, Alcaide-Loridan C, Middendorp S. Nanog and Oct4 overexpression increases motility and transmigration of melanoma cells. J Cancer Res Clin Oncol 2012; 138: 1145-1154.
33 Govaert KM, Emmink BL, Nijkamp MW, Cheung ZJ, Steller EJA, Fatrai S et al. Hypoxia after liver surgery imposes an aggressive cancer stem cell phenotype on residual tumor cells. Ann Surg 2014; 259: 750-759.

34 Chen L, Endler A, Shibasaki F. Hypoxia and angiogenesis: regulation of hypoxiainducible factors via novel binding factors. Exp Mol Med 2009; 41: 849-857.

35 Mathieu J, Zhang Z, Zhou W, Wang AJ, Heddleston JM, Pinna CM et al. HIF induces human embryonic stem cell markers in cancer cells. Cancer Res 2011; 71: 4640-4652.

36 Heddleston JM, Li Z, McLendon RE, Hjelmeland AB, Rich JN. The hypoxic microenvironment maintains glioblastoma stem cells and promotes reprogramming towards a cancer stem cell phenotype. Cell Cycle 2009; 8: 3274-3284.

37 Watanabe Y, Yoshimura K, Yoshikawa K, Tsunedomi R, Shindo Y, Matsukuma S et al. A stem cell medium containing neural stimulating factor induces a pancreatic cancer stem-like cell-enriched population. Int J Oncol 2014; 45: 1857-1866.

38 Charles N, Holland EC. Brain tumor treatment increases the number of cancer stem-like cells. Expert Rev Neurother 2009; 9: 1447-1449.

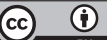

This work is licensed under a Creative Commons Attribution 4.0 International License. The images or other third party material in this article are included in the article's Creative Commons license, unless indicated otherwise in the credit line; if the material is not included under the Creative Commons license, users will need to obtain permission from the license holder to reproduce the material. To view a copy of this license, visit http://creativecommons.org/licenses/ by/4.0/

(c) The Author(s) 2017

Supplementary Information accompanies the paper on the Cell Death and Discovery website (http://www.nature.com/cddiscovery) 